\title{
Differences between three inbred mouse strains on a wheel-turn avoidance task'
}

DOMINIC J. ZERBOLIO, JR.

UNIVERSITY OF MISSOURI AT ST. LOUIS

\begin{abstract}
$\mathrm{C} 57 / \mathrm{BL} 6, \mathrm{BALB} / \mathrm{c}$ and $\mathrm{C} 3 \mathrm{H}$ mice were examined for differences in the acquisition and maintenance over sessions of wheel-turn avoidance response. The C57/BL6 s performed best and the BALB/cs worst on the first day. But the BALB/ cs reached and maintained the best avoidance level and the $\mathrm{C} 3 \mathrm{Hs}$ showed the worst maintenance. Initial day avoidance rates are viewed as related to the compatibility between the initially emitted responses of the different strains to the situation and the specific task-required response. Differential strain response to the US level are suggested as accounting for maintenance level differences.
\end{abstract}

Many studies have shown marked behavioral differences between strains on many tasks (Thompson, 1953; McClearn, 1958, 1964). But, current data show that selective breeding for specific behaviors per se (Heron, 1935; Tryon, 1940) are not necessary to produce behaviorally different organisms. One way to view strain differences is to examine types of responses emitted by specific strains in a test situation. When the emitted response is compatible with the task required response, initial performance should be quite good. If emitted responses and required response are incompatible, the reverse should occur. In the present study, three inbred mouse strains were examined on their original performance and maintenance of performance of wheel turn avoidance task. Also, original response emission for the three strains was observed.

\section{Method}

Six naive 40 day old male mice from each of three strains: C57/BL6, $\mathrm{C} 3 \mathrm{H}$, and $\mathrm{BALB} / \mathrm{c}$, obtained from Simonsen's in Gilroy, Calif. three weeks before the onset of the experiment, were housed in strain pairs (two per cage) during the experiment. All Ss were run in two similar 4 in. $x$ 6-1/2 in. $x$ 5-1/2 in. high wheel-turn boxes. Each box was constructed of $1 / 4$ in. plastic stock, and a $2-1 / 2$ in. long $x 2-1 / 4$ in. in diameter wheel, covered with aluminum screening, was mounted on the 5 in. wall. The boxes were similar in design and operating characteristics to those described in Zerbolio et al (1965) but adapted in size for mice. A 4000 cps 68-70 dB tone, produced by a Sonalert Module mounted on the plastic lid served as the CS. A 1.5 ma constant current shock delivered through a relay scrambler was the US. Separate refrigerator shells, with viewing ports and baffled exhaust fans, housed each box. All Ss received 50 trials a day for eight consecutive days. Each $\mathrm{S}$ re- ceived one additional 200-trial session on day 9,10 , or 11. Two Ss of each strain were run on days 9,10 , or 11. The ITI was a VI $40 \mathrm{sec}$, ranging from $20-60 \mathrm{sec}$. by $10 \mathrm{sec}$. jumps. The CS-US interval was $5 \mathrm{sec}$. The US was terminated automatically after $5 \mathrm{sec}$. if $S$ did not wheel-turn. A 1/4 turn or less was sufficient to terminate either CS or US. In addition, Ss were observed during sessions to determine responses emitted in the situation, but these data were not quantitatively gathered.

Resulis

Figure 1 shows the mean avoidance rate and the mean square root wheel-turn (WT) rates by days of training and strain. Both WT and avoidance rate were analyzed by a 3 strains by 8 days repeatedmeasures analysis of variance (Winer, 1962). The individual WT rates were subjected to a square-root transformation to reduce the mean-variance correlation and facilitate analysis. The analysis showed no differences between strains on WT $(F=1.48, \mathrm{df}=2 / 15$, $p>.05)$, but a significant training effect $(F=5.53$, $\mathrm{df}=7 / 105, \mathrm{p}<.01$ ), and a significant strains by training interaction $(F=3.91, d f=14 / 105, p<.01)$. The analysis of the avoidance performance data show significant differences between strains $(F=3.82$, df $=2 / 15, p<.05)$, a significant training effect $(F=30.74, d f=7 / 105, p<$ $.01)$, and a significant strain by training interaction $(F=4.47, \mathrm{df}=14 / 105, \mathrm{p}<.01)$. The source of these interactions is evident from Fig. 1. Note that the different strains' avoidance performances were fairly

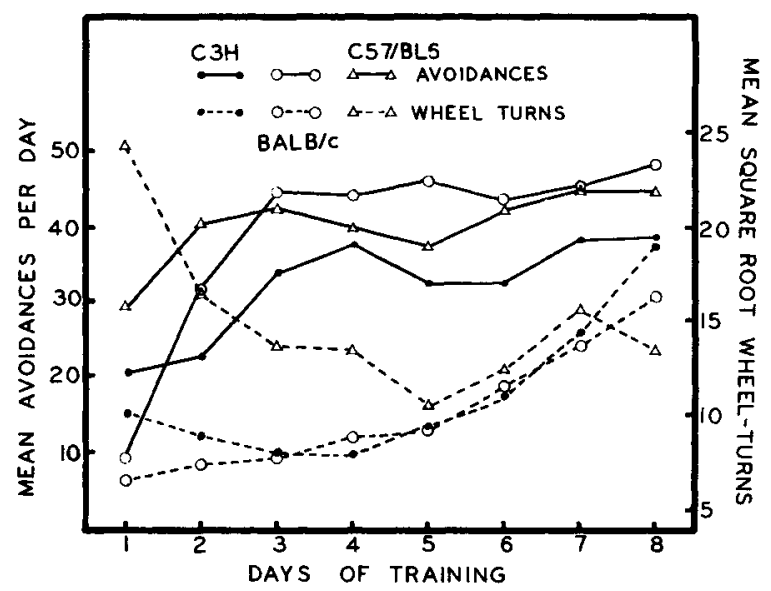

Fig. 1. The mean avoidance performance and mean square-root wheel-turn performance for the BALB/C, C57/BL6, and C3H strains per daily session for eight consecutive days. 


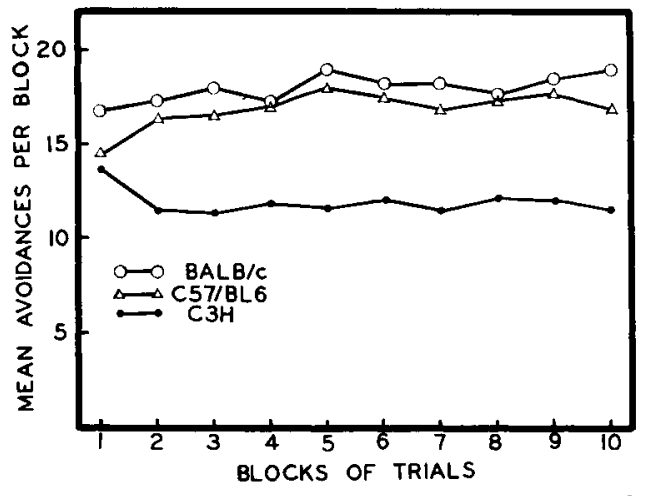

Fig. 2. The mean number of avoidances per block for 10 blocks for the BALB/c, C57/BL6, and C3H strains.

well stabilized by the fourth day of training while wheel-turn performance was not. This probably is why significant strain differences in WT rate were not found.

On days $4-8$, the $\mathrm{C} 3 \mathrm{H}$ strain showed a lower avoidance performance than the BALB/cs or the C57/BL6s. The additional 200-trial session, shown in Fig. 2, was run to examine this. These data show significant strain differences $(F=7.86, d f=2 / 15, p<.01)$ but no significant training $(F<1)$ or strain by training interaction effects $(F<1)$, indicating asymptotic avoidance performance had been reached by this time. In addition, no strain differences on transformed $\mathrm{WT}$ rates were shown by a one-way analysis of variance for this extended session $(F<1)$.

\section{Discussion}

This study, as in others dealing with different genetic material, finds large differences between strains. Strains were found to differ in both original learning and maintenance of WT avoidance performance. Clearly differences in original learning exist between strains (Fig. 1). Qualitative observations of differential initial response tendencies help clarify these differences. The C57/BL6s responded to shock by jumping. This jumping response was highly compatible with the WT response because Ss would land on the wheel, turn it, and terminate the US. By contrast, the BALB/cs initially ran when shocked. The running response, which is relatively incompatible with the WT response, produced poor initial avoidance performance. The C3Hs initially showed many jumping responses, which in later sessions changed to "dancing responses." The effect of compatibility of initially elicited and task-required responses is evident in Fig. 1. Also, Fig. 1 shows a negative relationship between avoidance performance and WT rate for the $\mathrm{C57} / \mathrm{BL} 6 \mathrm{~s}$ and $\mathrm{C} 3 \mathrm{Hs}$, and a marked increase in avoidance performance without a similar increase in WT performance for the BALB/cs. This suggests that first day avoidance performance is related to initial re- sponse emission but that subsequent performance is not and shows the advantage of running for several consecutive sessions.

Strains also differ in asymptotic avoidance level reached. Figure 2 shows the C3Hs markedly inferior

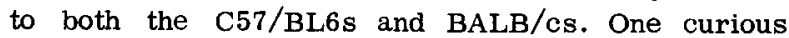
finding is the "reverse warm-up effect" the C3Hs shown in this extended session. A possible explanation for the inferior performance of the $\mathrm{C} 3 \mathrm{Hs}$ is that the US is an insufficient reinforcer. Thompson's (1953) finding of differences between strains on a "Food Drive" measure suggests this kind of effect. Assuming the US level is low enough to allow the $\mathrm{C} 3 \mathrm{Hs}$ to habituate to it would explain their "dancing" responses and "reverse warm-up" as well as their poor performance. But McClearn (1964) shows C3Hs make more repetitive errors in maze learning than other strains indicating they are inferior learners. Thus, the issue of $\mathrm{C} 3 \mathrm{H}$ performance remains an empirical question.

In this study, the initial emission rates of taskcompatible responses nicely account for differences in original learning. However, initial WT rates do correspond with strain differences on activity and exploratory measures previously found (Thompson, $1953,1956)$. But analysis of strain emission rates of task-compatible responses should be helpful in understanding differences between strains, especially where different comparison measures are used.

\section{References}

Heron, w. T. The inheritance of maze learning ability in rats. $J$. comp. physiol. Psychol., 1935, 19, 77-89.

McCleam, G. E. Performance differences among mouse strains in a learning situation. Amer. Psychologist, 1958, 13, 405. (Abstract) McCleam, G. E. Genotype and mouse behaviour. Proc. XI Int. Cong. Genet., 1964, Vol. I, 795-805.

Thompson, W. R. The inheritance of behaviour: Behavioural differences in fifteen mouse strains. Canad. J. Psychol., 1953, 7, 145-155.

Thompson, W. R. The inheritance of behavior: Activity differences in five inbred mouse strains. J. Hered., 1956, 47, 147-148.

Tryon, R. C. Genetic differences in maze learning ability in rats. In G. M. Whipple (Ed.), Yearbook of the National Society for the Study of Education. 1940. Part 1, p. 111-119.

Winer, B. J. Statistical principles in experimental design. New York: McGraw-Hill, 1962.

Zerbolio, D. J., Reynierse, J. H., Weisman, R. G., \& Denny, M. R. Pseudoconditioning? J. comp, physiol. Psychol., 1965, 59, 271274.

\section{Note}

1. This study was supported by USPHS grants $\mathrm{MH} 07015$ and $\mathrm{MH}$ 10261 awarded to Dr. J. L. McGaugh while the author was an NIMH Post Doctoral fellow at the Department of Psychobiology, University of California at Irvine. 